\title{
Continuous assessment of performance in External Quality Assessment Schemes
}

\author{
J C Ardern, K Hyde, L Hickman, A Urmston, R Burgess, A M Burn, C G Geary
}

\begin{abstract}
A simple, standardised procedure was used for processing data from External Quality Assessment Schemes and for producing performance charts. A graphic presentation of cumulative performance is generated for each test, using an integrated software package to display results in a standardised format. This permits interpretation of satisfactory and poor performances and facilitates identification of "outlying" results. Although most results are recorded as Deviation Indices, the system is flexible and can be used to present other performance variables, such as Percentage Deviations and relevant textual information relating to interpretative assessments. It is therefore readily adaptable for use by other pathology disciplines.
\end{abstract}

More than 600 laboratories participate in the National External Quality Assessment Scheme for Haematology (NEQAS(H)), ${ }^{1}$ reflecting the importance given by laboratories to external quality assessment (EQA). Independent assessments of the accuracy and precision of the results reported by participating laboratories are an essential component of haematological practice. As more schemes or tests are introduced, however, the demands made on scarce laboratory resources are increased.

The Department of Haematology at the Manchester Royal Infirmary is located on four sites and participates in the NEQAS $(H)$ blood coagulation, blood group serology, and general haematology schemes. Two Interregional Quality Assurance Schemes (IRQAS)_one for haematinics (Department of Haematology, Good Hope Hospital, Sutton Coldfield), one for immunocytochemistry ${ }^{2}$ (Department of Haematology, Northern General Hospital, Sheffield)-and the North West Regional Quality Assurance Scheme for haemoglobinopathies ${ }^{3}$ are also undertaken. Samples are analysed, usually on a monthly basis, by the four main sections-blood counts, haemostasis, haematinics and haemoglobinopathies. In the past EQA reports arrived directly in the individual sections. It was the responsibility of staff in these areas continually to assess their performance and to communicate the information to colleagues. Managers of the sections processed their EQA reports in various ways, but agreed that they were becoming overloaded with data. Staff often found the documentation bulky, time-consuming to read, and difficult to interpret; in some cases Deviation Indices (DI), ${ }^{4}$ an assessment of a laboratory's performance, were not provided.

In 1989 the department received EQA reports for more than 600 tests. The reports were presented in several formats and we required an effective and efficient method of processing the data. Over 12 months actions were taken to relieve the problems highlighted and to provide a data reduction system which would cater for current and projected needs.

\section{Methods}

A member of staff was designated quality assurance coordinator as part of their duties. This person provided a central reference point for receipt and distribution of samples from the various EQAS which had previously been the responsibility of the departmental sections. As each set of EQAs samples was received the quality assurance coordinator photocopied the trial information for central records and distributed the samples immediately. After sample processing, a copy of the results sheet was returned to the coordinator and the original despatched to the trial organiser.

For data handling an integrated software package, Smartware II (Informix Software Ltd, Ashford, Middlesex), consisting of a word-processor, spreadsheet, and database was used on an IBM compatible personal computer. The spreadsheet facility was used for storage of raw EQAS data and subsequent production of graphs in a standardised format. The spreadsheet consists of a series of cells for storing numerical and textual data identified by a column and row number. A total of 999 columns and 9999 rows are available for use in each spreadsheet. For convenience, a separate spreadsheet was generated for each section of the department and each test performed allocated to a column. For example, the blood coagulation spreadsheet included prothrombin time, activated partial thromboplastin time, thrombotest time, factor VIII:c, fibrinogen, von Willebrand antigen and heparin dose assessment. In trials where more than one sample was provided for a particular test (three samples for prothrombin time) or where more than one method of analysis (two Coulter Counters) were used, additional columns were allocated. Trial number and date of return were placed in rows and were extended as each trial was completed.

On receipt of an EQAS report the quality 
Table 1 NEQAS prothrombin time Percentage Deviation

\begin{tabular}{|c|c|c|c|c|}
\hline \multicolumn{2}{|l|}{ Sample } & \multirow[b]{2}{*}{$P T-(A)$} & \multirow[b]{2}{*}{$P T-(B)$} & \multirow[b]{2}{*}{$P T-(C)$} \\
\hline Trial No & Date of sample & & & \\
\hline $\begin{array}{l}8862 \\
8963 \\
8964 \\
8965 \\
8966 \\
9067\end{array}$ & $\begin{array}{l}\text { Oct } 88 \\
\text { Feb } 89 \\
\text { May } 89 \\
\text { Aug } 89 \\
\text { Nov } 89 \\
\text { May } 90\end{array}$ & $\begin{array}{r}4 \cdot 40 \\
16 \cdot 40 \\
0.00 \\
6 \cdot 80 \\
-3 \cdot 18 \\
10 \cdot 26\end{array}$ & $\begin{array}{r}3.30 \\
19.90 \\
0.00 \\
1.60 \\
-4.04 \\
2.57\end{array}$ & $\begin{array}{l}8 \cdot 10 \\
13 \cdot 50 \\
\mathrm{~N} / \mathrm{T} \\
\mathrm{N} / \mathrm{T} \\
\mathrm{N} / \mathrm{T} \\
\mathrm{N} / \mathrm{T}\end{array}$ \\
\hline
\end{tabular}

PT $=$ prothrombin time.

(A), (B), (C) = sample code

$\mathrm{N} / \mathrm{T}=$ not tested. assurance coordinator entered the DIs into the appropriate spreadsheet column for longterm storage. If a DI was not provided it was calculated manually and entered. A simple line graph was then generated for each variable of DI $v$ time. Data from a maximum of six columns may be used in the generation of the graph which provided a cumulative assessment of performance in successive trials. Individual graphs can be combined into a composite performance chart with up to four graphs per A4 page. For those tests where a
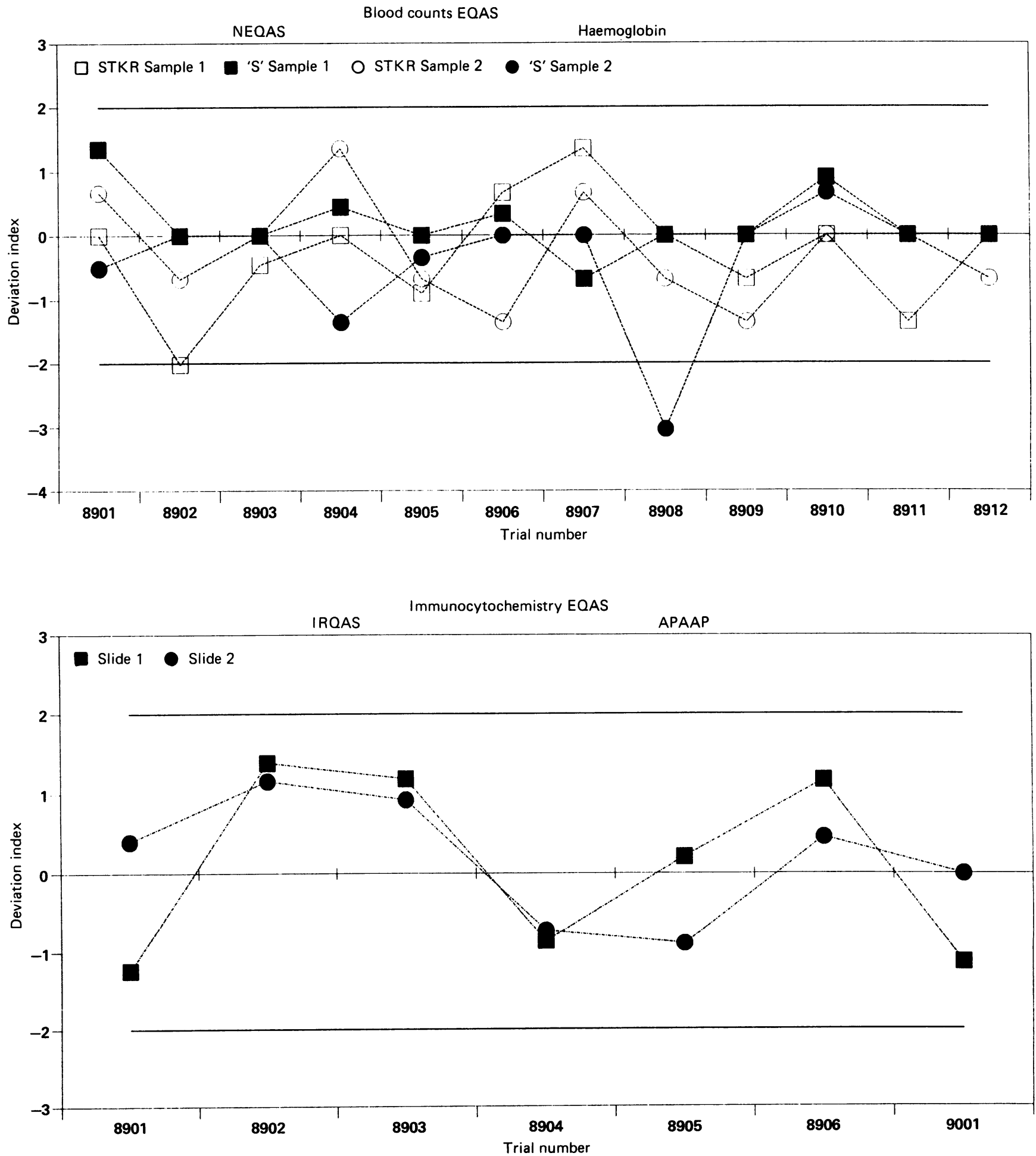
DI was appropriate satisfactory performance limits of $+/-2.0$ were indicated on each graph. For other tests, results within 15\% above and below the median were regarded as satisfactory performance.

The original EQAS report was returned to the relevant section for more detailed study if required, together with the "in-house" generated performance charts. The charts were posted on designated internal quality control and EQAS notice boards outside each section. A monthly graphical summary of EQAS information was also provided to the departmental director, manager, and appropriate medical staff.

A recent development for the haematinic section has been the provision of an additional spreadsheet, providing details of the interpretation of our results whether low, normal, high or indeterminate, compared with the consensus interpretation.

\section{Results}

An example of Percentage Deviations entered into the coagulation spreadsheet is shown in table 1 . In this reduced version only columns allocated to prothrombin time results are shown. When sufficient data have been collected, several statistical calculations can be made, including annual DI and the number of results exceeding the satisfactory performance limits. Similar spreadsheets were used for generating the graphs which show our performance in NEQAS haemoglobin and IRQAS immunocytochemistry trials (fig 1). Normally the composite performance charts of relevant EQAS information are produced on a sectional basis. The laboratory's performance may be inferred from the DI by the closeness of the DI to zero, indicating ideal performance. For results which exceed the two solid lines denoting satisfactory performance (+/- DI 2.0)-for example, haemoglobin-trial number 8908 , sample 2 would be investigated. In this case the actual value reported was not significantly different from the median value in clinical terms, the difference being $0.7 \mathrm{~g} / \mathrm{dl}$.

When interpreting performance, notice should also be taken of results which do not exceed $+/-$ DI $2 \cdot 0$. Trends may be detected and differences in DI between two samples in a trial are readily identified. Differences should

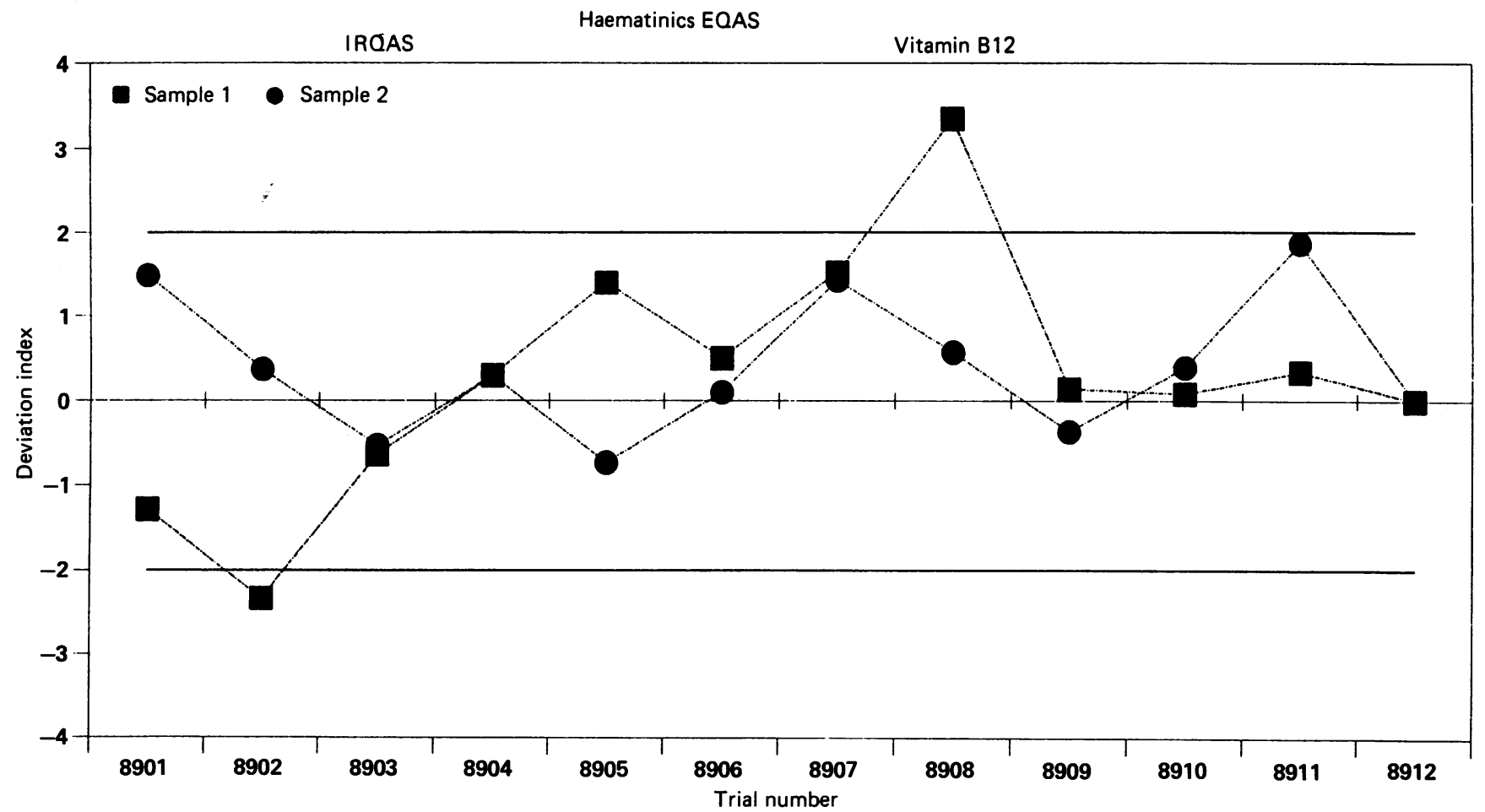

Figure 2 Cumulative performance chart for IRQAS vitamin B12 trials.

Table 2 IRQAS Vitamin B12 interpretative assessments

\begin{tabular}{|c|c|c|c|c|c|c|}
\hline $\begin{array}{l}\text { Date } \\
\text { Trial number } \\
\text { Sample number }\end{array}$ & $\begin{array}{r}\text { June } \\
8906 \\
1\end{array}$ & $\begin{array}{r}\text { June } \\
8906 \\
2\end{array}$ & $\begin{array}{r}\text { July } \\
8907 \\
1\end{array}$ & $\begin{array}{r}\text { July } \\
8907 \\
2\end{array}$ & $\begin{array}{l}\text { August } \\
8908 \\
1\end{array}$ & $\begin{array}{l}\text { August } \\
8908 \\
2\end{array}$ \\
\hline $\begin{array}{l}\text { Our results } \\
\text { Our group mean }\end{array}$ & $\begin{array}{l}434 \cdot 0 \\
391 \cdot 0\end{array}$ & $\begin{array}{l}424 \cdot 0 \\
410 \cdot 4\end{array}$ & $\begin{array}{l}485 \cdot 0 \\
371 \cdot 0\end{array}$ & $\begin{array}{l}502.0 \\
390 \cdot 0\end{array}$ & $\begin{array}{l}720 \cdot 0 \\
430 \cdot 8\end{array}$ & $\begin{array}{l}396.0 \\
355.3\end{array}$ \\
\hline $\begin{array}{l}\text { Interpretation } \\
\text { Low } \\
\text { Normal } \\
\text { High } \\
\text { Indeterminate } \\
\text { Ours }\end{array}$ & $\begin{array}{c}0 \\
164 \\
0 \\
0 \\
\text { Normal }\end{array}$ & $\begin{array}{c}2 \\
154 \\
1 \\
0 \\
\text { Normal }\end{array}$ & $\begin{array}{c}0 \\
186 \\
0 \\
0 \\
\text { Normal }\end{array}$ & $\begin{array}{c}0 \\
178 \\
2 \\
1 \\
\text { Normal }\end{array}$ & $\begin{array}{c}0 \\
181 \\
0 \\
0 \\
\text { Normal }\end{array}$ & $\begin{array}{c}1 \\
178 \\
0 \\
0 \\
\text { Normal }\end{array}$ \\
\hline
\end{tabular}


be minor and random. Several factors, however, may contribute including differences between types of sample in a trial, for example, the use of human, equine, and avian cells or additional manipulative treatment of one sample. Furthermore, difficulty in interpretation of performance may be experienced when minor differences in reported values appear significantly different due to using the DI as a measure of performance. For example, in trial number 8902 (fig 1) the difference between our reported haemoglobin result and the group median for STKR samples 1 and 2 was $0.3 \mathrm{~g} / \mathrm{dl}$ and $0 \cdot 1 \mathrm{~g} / \mathrm{dl}$, respectively.

The advantage of combining graphical with interpretative information is illustrated for vitamin B12 assays (fig 2) (table 2). The performance chart shows that a DI of 3.2 was scored for sample 1 in trial 8908. A reduced example of the interpretative assessment worksheet (table 2) indicated that, although our result was higher than the group mean, the interpretation was in agreement with the consensus.

\section{Discussion}

We required a simple practical approach to assess our performance in EQAS with efficient processing of data. We devised a system to organise and process all our EQAS data in the same manner, regardless of source, with a final stage of generating cumulative summaries of performance. Most data are reduced to graphs of the DI against time for each test. A performance chart consisting of a composite display of up to four graphs per A 4 page condenses the number of sheets to be examined and reduces paper generation. The interpretative assessments provided for haematinic trials have proved useful for identifying discrepancies between assay values, and the consensus interpretation and will be extended to the coagulation trials.

The DI is used in most cases to present performance data and affords the advantages of allowing accuracy for different samples and variables to be compared readily. A specific "group DI" rather than the "All method DI" is used. This overcomes a potential interpretative problem arising when analysis for a particular test is made by two or more different systems.

A statistical background is not required either by the quality assurance coordinator to use the programs, or by members of staff examining the final copies. By using graphs to present results in a standardised, integrated, and condensed form, interpretation of performance has been reduced to deciding whether results lie between the two lines which delineate acceptable limits.

These summaries have been used at various regional meetings for peer group comparison with other laboratories. This system has also proved beneficial to more junior members of staff: they have become more aware of the importance of EQAS, and the graphs generate interest when displayed on the notice boards.
By centralising the EQAS processing, managerial and technical improvements have resulted. For example, familiarity with the different schemes has been acquired by the coordinator through continued exposure and it is now a simple matter to extract the DIs or raw data for calculation. The coordinator is therefore seen as a point of reference for queries from all staff. Now that the system is operational and the quality assurance coordinator has gained experience, the time taken to process the data is small compared with that taken by each individual section performing the same functions.

Although the quality assurance coordinator undertakes a key role in the process this function is not necessarily limited to a single individual; in fact the coordinator has a named deputy able to fulfil the initial sample distribution and result collection roles. Input of data to the spreadsheet and graph production can be made by clerical or scientific staff, although final graph generation is usually made by the quality assurance coordinator.

The use of spreadsheets on a computer system provides for long term storage of our EQAS studies and is flexible enough to allow additional information to be readily accommodated as new tests have been introduced. Once the initial process for producing a graphical printout had been defined, the extension of the spreadsheet does not affect previously entered data. The use of other variables of performance can also be incorporated-for example, the Variance Index; this should make the system adaptable for use by other pathology disciplines. There is no absolute requirement to use Smartware II as other spreadsheet programs with adequate graphics facilities should be adaptable.

In future, the benefits of an integrated package will enable the use of the word-processor for input of textual information. This would be useful when DIs exceed the acceptable limits, and specific details or a description of the possible cause or reasons for the deviation will be recorded. Furthermore, we now fax some of our interregional results. The NEQAS (general) organiser and Steering Committee have approved a pilot experiment to investigate electronic transfer of results and reports between the organisers' and participants' computers to aid efficient data handling. The specification for these interchanges is currently underway. Success in this pilot experiment will provide an efficient extension to the department's current computerised assessment of performance in EQAS.

1 Ward PG, Lewis SM. Interlaboratory trials: a nationa proficiency scheme in Britain. In: Lewis SM, Coster JF eds. Quality control in haematology. London: Academic Press, 1075:37-51

2 Forrest MJ, Barnett D. Laboratory control of immunocytochemistry. Eur J Haematol 1989;42:67-71.

3 Edwards N, Hyde K, Baylis PR, Ardern JC. North Wes Regional Quality Assessment Scheme for Haematology. Med Lab Sci 1986;(Suppl 1)43:24.

4 Lewis SM. External Quality Assessment in Europe. In Rowan RM, England JM, eds. Automation and quality assurance in haematology. London: Blackwell Scientific Publications, 1986:18-61. 